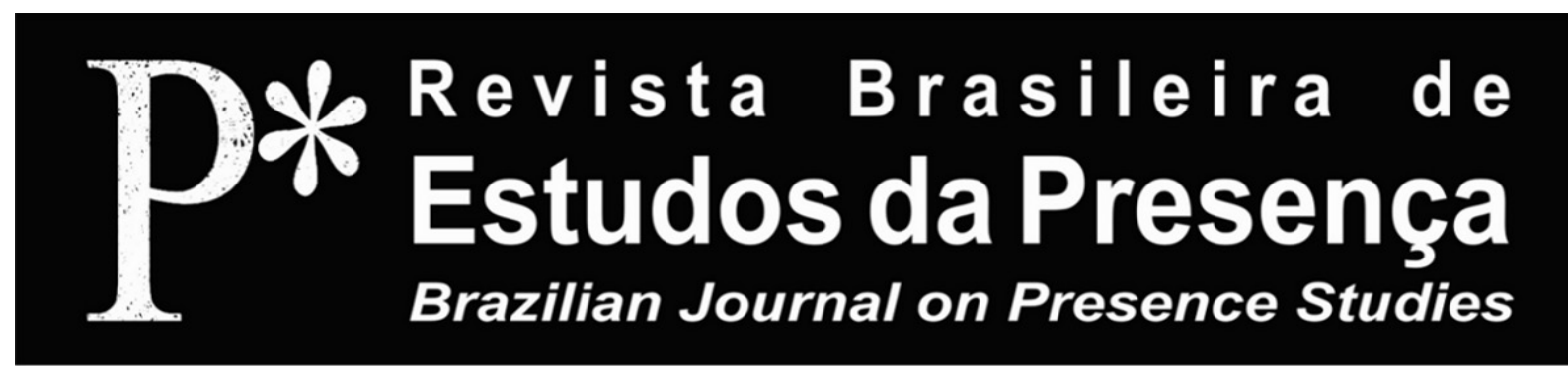

DOI - http://dx.doi.org/10.1590/2237-266042979

ISSN 2237-2660

\title{
Time Trails: presencing digital heritage within our everyday lives
}

Gabriella Giannachi

William Barrett

University of Exeter - Exeter, England

Paul Farley

Exeter City Football Club Supporters Trust - Exeter, England

Andy Chapman

1010 Media - Exeter, England

Thomas Cadbury

Rick Lawrence

Helen Burbage

Royal Albert Memorial Museum and Art Gallery - RAMM, Exeter, England

ABSTRACT - Time Trails: presencing digital heritage within our everyday lives ${ }^{1}-$ The Time Trails project is a collaboration between the Centre for Intermedia at the University of Exeter, Royal Albert Memorial Museum and Art Gallery, 1010 Media, and Exeter City Football Club Supporters Trust (2013). It is a mobile web app to allow users to follow, annotate and create trails using text, images and videos, and to respond to them via social media. Two trails narrating the history of Exeter City Football Club and its Supporters Trust, used for mobile learning and as part of sport and cultural tourism experiences are presented. We show how Time Trails can be used as a presencing tool to establish new ways of encountering and learning on digital heritage within our daily lives.

Keywords: Presencing. Digital Heritage. Mixed Reality. Trajectories. Community.

RÉSUMÉ-Time Trails: patrimoine numérique en présence dans notre quotidien - Le projet Time Trails est le résultat d'une collaboration entre le Centre for Intermedia de l'University of Exeter, le Royal Albert Memorial Museum and Art Gallery, le 1010 Media et l'Exeter City Football Club Supporters Trust (2013). C'est une application web conçue pour des dispositifs mobiles et qui permet aux usagers de suivre, de commenter et de créer des scénarios en utilisant du texte, des images et des vidéo, diffusés via les réseaux sociaux. Deux scénarios racontant l'histoire de l'Exeter City Football Club et de son Supporters Trust sont présentés et utilisés pour l'apprentissage via mobile. Ils font partie d'une expérience sur le tourisme sportif et culturel. Nous montrons aussi comment le Time Trails peut être utilisé en tant qu'outil de présence pour établir de nouvelles manières de rencontre et d'apprentissage sur le patrimoine numérique dans notre quotidien.

Mots-clés: Présence. Patrimoine Numérique. Réalité Mixte. Trajétoires. Communauté.

RESUMO - Time Trails: patrimônio digital em presença no nosso dia a dia ${ }^{2}-\mathrm{O}$ projeto Time Trails é uma colaboração entre o Centre for Intermedia da University of Exeter, Royal Albert Memorial Museum and Art Gallery, 1010 Media e Exeter City Football Club Supporters Trust (2013). Trata-se de um aplicativo da web para dispositivos móveis que permite aos usuários seguir, comentar e criar roteiros usando texto, imagens e vídeos, respondendo via mídias sociais. Sáo apresentados dois roteiros, narrando a história do Exeter City Football Club e de seu Supporters Trust, que são usados para aprendizagem via celular e como parte de experiências em turismo esportivo e cultural. Mostramos como o Time Trails pode ser usado como uma ferramenta de presença para estabelecer novas maneiras de encontro e aprendizagem sobre patrimônio digital em nosso dia a dia.

Palavras-chave: Presença. Patrimônio Digital. Realidade Mista. Trajetórias. Comunidade. 
Time Trails was a collaboration between Royal Albert Memorial Museum and Art Gallery (RAMM), 1010 Media, The Centre for Intermedia at the University of Exeter and Exeter City Football Club Supporters Trust, funded by Research and Enterprise in Arts and Creative Technology - Higher Education Innovation Funding (REACT-HEIF) in 2013. The project aimed to develop a web app prototype based on RAMM's existing tours website, modelled on the Exeter Time Trail website which is widely used by the British Broadcasting Corporation (BBC) and Usborne, through which users could explore different objects in RAMM's collections via three types of tours: Museum tours, linking objects on display; Exeter tours, presenting Exeter's history through the archaeological record and material culture of Exeter; and Devon tours, linked to exhibitions, and encouraging the exploration of Devon's wider heritage. Building on RAMM's tour website, the Time Trails project aimed offer users the experience of learning about and engaging creatively with history, heritage and RAMM's collections through a series of time trails that can be experienced both inside and outside the museum whilst on the go. Additionally, the web app was developed so as to allow users not only to experience trails curated by RAMM (e.g., historic trails, such as our Roman, Tudor, Victorian, and World War 2 trails or thematic trails, such as life-style and sport trails), or project partners, such as Exeter City Football Club Supporters Trust, but also annotate these trails through social media and, in a subsequent stage of development, generate their own trails. Finally, Time Trails could be used as explorative teaching tools to facilitate mobile interpretation and free-style mobile learning; to generate appreciation of heritage and visual and material culture; as an aid to tourist guides or as cultural tourism maps; to promote leisure, sport and businesses; to facilitate reflection and stimulate a sense of presence and identity among different communities. This article will focus specifically on how Time Trails was used towards the latter and show how initial findings support the hypothesis that Time Trails can act as a presencing tool.

The Time Trails project drew on two bodies of research, bringing together findings in relation to the use of trajectories for the design of mixed reality experiences (Benford; Giannachi, 2011) with studies on what constitutes presence in live, mediated and simulated environments (Giannachi; Kaye, 2011, Giannachi, 2012). Here we 
will explain how the Time Trails tool was conceived of and how initial trails were designed drawing on these distinct but complementary bodies of research grounded, respectively, in Human Computer Interaction (HCI) and Performance Studies, and in Game Studies and in Performance Studies and New Media, to stimulate users' sense of presence in relation to the history of a particular community, that of Exeter City Football Club and the Supporters Trust that, since 2003, owns the Club. Before we move on to show how the tool was developed and how the trails were designed towards this goal, we need to briefly illustrate salient findings of research into mixed reality environments and presence to explain how we arrived at the formulation that Time Trails can be used as a presencing tool.

Mixed reality experiences are ones that span physical and digital environments (Milgram; Kishino, 1994) and often entail forms of interactive, distributed, and subjective performance (Benford; Giannachi, 2011), by which we mean that users of such environments are encouraged to perform actions or embrace forms of more or less minimal role-play. Well-known examples of mixed reality environments are those created by United Kingdom (UK) company Blast Theory, such as, to cite an example that was influential for the conception of this project, the hybrid performance-game Rider Spoke (2007), during which participants cycled for about an hour through the streets of a city equipped with a handheld computer, listening to recordings made by other participants and making their own recordings of their personal memories in response to questions prompting them to read specific urban locations in relation to aspects of their lives. With the company selecting, each evening, the best recordings to become part of the work, Rider Spoke can be described as the result of a process of collective authorship, a potentially infinite archive, embedding personal histories within urban locations for others to encounter. As with other mixed reality works, in Rider Spoke the experience of the environments that emerge from the overlay of digital information with physical spaces is carefully designed and, as far as possible, pre-scripted, to facilitate a rewarding, interactive, comprehensible, safe, and more or less pervasive form of engagement. We drew inspiration from Blast Theory's Rider Spoke in identifying strategies to prompt users to reinterpret a set of physical locations in relation to their own history and adopted the trajectories framework, 
which was drawn from a number of mixed reality works, including Rider Spoke, to achieve this objective.

The trajectories framework was developed to provide a means to design and interpret mixed reality experiences (Benford; Giannachi, 2011) and has since been utilised in a variety of contexts. According to Benford and Giannachi, trajectories define "[...] predicted and actual itineraries through mixed reality experiences" (2011, p. 15). They are predicted in the sense that they express a desired set of routes participants may follow, and actual, in the sense that they can show how participants choose to behave whilst on the go. Two types of trajectories were deemed to be particularly useful in the context of the design of physical trails entailing a time-driven narrative: trajectories through space and trajectories through time. As mixed reality environments are hybrid, different spatio-temporal conventions are used, often concurrently. The trajectories framework helps to plan how users may behave as they embrace a variety of more or less active roles (e.g. spectating, interacting, acting, documenting, doing etc.) to deal with the shifts necessary in moving from one set of spatio-temporal conventions to the next. Before explaining precisely what this means within the context of a mapping and map-making experiences such as that offered by Time Trails, we need to describe more specifically what kind of spatio-temporal conventions tend to be adopted in mixed reality experiences.

We know from the work of Henri Lefebvre that space consists of the variable interfacing between perceived, conceived and lived space (Lefebvre, 1992) and we know that space can be the result of the juxtaposition of physical and cultural spaces spanning both physical and digital environments (Benford; Giannachi, 2011, p. 44). We also know from Manuel Castells's work (1996) that there is a "space of places" which, Castells claims, is localised and associated with local history, tradition and memory, and a "space of flows" which is a-historical, location-free and continuous, though we think these spaces are never entirely separate in mixed reality environments and the sense of "augmentation" is in fact often reliant on the effect of their cohabitation. This means that, when designing a mixed reality experience, it is possible not only to generate an environment through which participants move from one of these spaces to another, but also to design displacements so that participants may be able to observe 
and reflect on one kind of space from another by embracing different types of roles. We will come back to how exactly we used the practice of displacing, for example between "canonical" trajectories, which are prescripted and embedded within a route, and "participant" trajectories, which are defined by participants, and are emergent and unpredictable (Benford; Giannachi, 2011, p. 235-236), and what this means in relation to the distinction between cultural and socially constructed, cartographic and lived in spaces, later in this article.

From a temporal point of view, the trajectories framework indicates that one can conceive of five layers of time in the kinds of interactive narratives that are usually used in mixed reality environments: perceived time ("[...] the timings of interactions as perceived by the participant"), interaction time ("[...] the times at which a participant chooses or is able to interact"), schedule time ("[...] the times at which the narration is made available"), plot time ("[...] the temporal structure of the narration of the story") and story time ("[...] the temporal structure of the underlying story world") (Benford; Giannachi, 2011, p. 96). Again, designers of mixed reality environments look at how participants inhabit multiple layers of time so that crucial factors, such as engagement and participation, can be designed and orchestrated throughout an experience. In the context of Time Trails, plot and story time played a particularly significant role, as we shall explain later in this article.

In terms of presence research, our thinking was influenced by the notion that presence emerges out of a set of relationships with one's environment (Giannachi, 2012, p. 50) because integral to an understanding of what constitutes presence is what is before or in front of a subject (Giannachi; Kaye, 2011, p. 4-9). In other words, presence is always contextual to the environment a subject finds him or herself in and, as no environment is ever complete because they are forged by living things (Ingold, 2000, p. 20), they are best described as processes rather than fixed locations, which means that one is only present in so far as one is part of and in relation with a set of environmental processes. In other words, presence is the network of processes that are involved as the subject redefines him or herself in relation to an environment that is in constant evolution. As such environments entail traces of past operations of presence, the subject may redefine their presence not only spatially but also temporally, by looking forward to what is evolving and is not yet present, as 
well as by looking backwards to the traces left by the past in the present. To put it with Edmund Husserl (1990), to construct one's being or presence in time we engage with processes of protention (the anticipation of the next moment in time) and retention (not so much a memory as the emergence of the present from the past).

Presence emerges from the subject's attempt to relate to a shifting environment. This means that presence can be described as an excess, trace, or, as suggested by Martin Heidegger, as what persists or perdures as a consequence of this process. Heidegger suggests:

The word 'being' now no longer means what something is. We hear 'being' as a verb, as 'being present' and as 'being absent'. 'To be' means to perdure and persist. But this says more than just 'last and abide'. 'It is in being' means 'it persists in its presence', and in its persistence concerns and moves us (Heidegger, 1971, p. 95).

For the context of this project, presence is therefore to be understood as what persists, a trace, from the process through which the subject relates to what is before or in front of it. More specifically, presencing becomes the act through which this excess, trace or persistence emerges. In the context of Time Trails, this means that if the web app is meant to operate as a presencing tool, facilitating the repositioning of the subject in relation to what is before or in front of them, it needs to not only offer information about one's environment, as most trail web app tools do, but also facilitate the understanding and stimulate a more performative engagement (which remains as trace) with both that environment and the history this may entail. It is in this encounter, we will show, that presencing occurs. We postulated that by facilitating Time Trails users in reflecting, documenting or sharing their experience of the trail, they would be encouraged to position themselves in relation to what was designed in a canonic trajectory (a history) and possibly be inspired to generate a participant trajectory (by telling their own story in relation to that history). This act of presencing encourages the user to position their personal story within a history through processes of retention and protention that allow them to relate to traces from the past, whilst generating new traces for the future. In this way users can connect their story to what has thus far persisted, a broader history, while generating the possibility of their own persistence as part of an unfolding communal narrative. 
Having elaborated on the research that set the agenda in terms of the design of the Time Trails user experience, we will now show how 1010 Media designed the Time Trails web app in consultation with a broad spectrum of stakeholders. We will also explain more fully how we came to design two Exeter City Football Club trails in collaboration with staff from Exeter City Football Club Supporters Trust. We will then discuss our initial findings in terms of presence research and show that mapping and map-making tools like Time Trails can be used for presencing to facilitate the creation, understanding and sharing of a common history among seemingly diverse communities.

Following a period of research and development which saw us consult with two primary schools in Exeter (St. Sidwell's Primary School and St. David's Primary School), Exeter City Red Coats Guides, and various members of the Exeter City Football Club Supporters Trust, 1010 Media developed the Time Trails web app together with a bespoke find me tool that allows users to identify their location using geocoding, so that the location may be imported into a trail and become a destination. The site allows users to take Devon tours, Exeter tours and RAMM tours. Once a tour is selected, the tool identifies the user's location through Global Positioning System (GPS) and places them on the map as a green dot if connectivity is good or an orange dot if it isn't. If the users are in the proximity of a trail, they can start it and progress through as many locations as they have time for. Alternatively, the app suggests that the user views the locations as a list. Once a location is encountered, the user can view it, move on or comment about it on twitter. When the location is then viewed, the icon on the map that represents it turns from red to green. The interface, which initially showed a map view, was changed to a hybrid view to create an enhanced sense of being in a location. Street view can also be used, and all settings can be erased so as to experience the tour afresh. We will come back later in this article to the significance of mapping and map making in this context.

A number of trails were designed. Two of these used RAMM's collections (a Tudor trail to coincide with an exhibition on Elizabethan art scheduled for October 2013 and a World War Two trail) and two utilized Exeter City Football Club Supporters Trust content (one was 
written for the general public and one was written specifically for the children taking part in the Football in the Community Kick Start programme, which supports children who are at risk of disengaging from education by delivering a personalized learning programme). Both Exeter City Football Club Supporters Trust trails, which this article focuses on, were designed by asking stakeholders to identify a set of locations in Exeter and at St. James Park, the stadium that is home to Exeter City Football Club, through which one could narrate the history of both the Club and the Trust that owns it.

Our brief from Exeter City Football Club Supporters Trust was to narrate the history of the Club from 1904, when the club was formed, to today, covering both its work as a sports Club and its social work as a Trust among diverse communities. We were told that we should attempt to narrate this history through the lives of well-known players and managers and by covering significant moments in time, such as the Club's formation in 1904; a historic match against Brazil played in 1914; the formation of the Trust that, since 2003, owns the club, among others. The overall length of the texts had to be about 150-200 words, which was estimated to offer a sufficient level of interpretation for a mobile device, and each entry could be accompanied by one image. Our starting point were the locations that had been selected by members of the Trust as they constituted the physical spaces that would form the environments encountered by the users whilst out and about. The locations not only had to be historically significant, sufficiently diverse, but also relatively safe, accessible and reachable as part of a walk. St. James stadium was selected as the first location and RAMM itself as the last location of the longer trail, so that users would be in the proximity of trails that utilised RAMM's own collections. The second, shorter trail, designed specifically for the children taking part in the Kick Start programme, had to start and end at St. James Park, where the programme was held.

The longer trail was designed for generic users to be illustrative of the history and role that Exeter City Football Club and Trust played in the history of the city of Exeter. Writing the history of the Club and Trust within specific locations in the city was part of our presencing strategy that aimed to integrate knowledge about the past within the fabric of present locations. Most locations had changed 
substantially, not only because those who were associated with them had died, but also because a large part of Exeter city centre was destroyed during the Second World War. This means that users would be asked to look, for example, at a Turkish supermarket whilst being given information about the Red Lion Inn, where, in 1904, delegates of Exeter United met with members of another local amateur side, St. Sidwell's United, and decided to merge to form the club we know today. This dislocation between past and present created a marked distinction between perceived and lived space.

Members of Exeter City Football Club Supporters Trust worked with us on a set of twenty-five locations in Exeter and an additional eleven at St. James Park, from which we selected twenty-three locations that lead to a semi-linear walk lasting approximately one hour and a half for the longer trail, and twelve locations that lead to a circular walk lasting approximately one hour for the shorter trail. St. James Park was selected to be the starting location for both trails, as it introduces the history of the grounds and one of the most significant figures in the history of the Club, Sid Thomas, whose career with the club was to last over seventy years not only as a player, but also a secretary, director, chairman and lifelong president. Generally speaking, facts and histories were narrated using the third person; contemporary oral and personal histories were narrated in first person, or using pluralia majestatis; and questions were asked at the end of the interpretation text to prompt affordances using second person. These aimed to encourage users to respond by adopting first person to write their own story within the broader history of Exeter City Football Club and Trust. Thus users, having seen the information text about the past, would progressively become more involved by being addressed through the use of second person and finally become part of that history by using first person. Location 1 shows how we played with distancing in this way:

Exeter City FC's first match was held here at St. James Park on 10th September 1904. The team won 2-1 against the 110th First Royal Artillery. The winning goal was scored by Sid Thomas, whose career with the club would go on to last over 70 years not only as a player, but also a secretary, director, chairman and lifelong president. When ECFC turned professional in 1908, St. James Park was developed to meet the standards of the Southern League. Despite a few games played elsewhere, this has been the home of 
Exeter City FC for over 100 years. Once there was a large gate here, the Kendall Gate. On a Friday in late February 1981, when we had an FA cup run, hundreds of supporters slept overnight on the pavement by that gate, so when the shop opened on the Saturday morning to sell tickets for the quarter final match away to Spurs we would not miss out. Were you there that night? Can you remember what you felt the first time you came here?

Some locations were dedicated to particular players so as to raise awareness of their achievements and remember them as pillars in the community by highlighting their educational role or charity work carried out by them or in their memory, such as the one below dedicated to Adam Stansfield.

Adam Stansfield (b. 1978) played a key role in Exeter City Football Club's promotion campaigns of 2008/09 \& 2009/10, scoring 37 goals during that time. Tragically, Adam died of bowel cancer on 10 August 2010, at the age of 31, prior to the start of the game against Ipswich. The news broke out on the Tuesday night, during the match, and started to spread through social media. The match the following Saturday was postponed. His legacy lives on through the Adam Stansfield Foundation, which aims 'to help give young people the unique opportunity to develop life skills, through the power of football and to assist them in their goals of living the dream'. A song dedicated to Adam is sung each week by the fans here at St. James and his number 9 shirt was retired by the club as a mark of respect for nine seasons. Look up, and you will see his memorial so that he may always be with us. You too can pay tribute to him by learning about the Foundation's activities.

Other locations were more explicitly dedicated to the presentation of particular historical facts, such as this location which raises awareness about the role played by Michael McGahey in the historic match against Brazil.

Michael John McGahey (b. 1873), whose family has run this tobacconist for four generations, was a local solicitor and Exeter City FC chairman when the club travelled to the continent of South America. It was during this tour that the side became forever known as 'Exeter City, da Inglaterra, o primero quadro profisional que jogou no Brasil' or 'Exeter City from England, the first professional team to play in Brazil'. During the tour City played the newly formed Seleção of Brazil in a game that ended 2-0 to the South Americans. Yet beyond the result, this fixture gave the fledgling republic a symbol of its identity and 
gives Exeter the distinction of being the first team ever to have played against the nation that would go on to win the World Cup five times! McGahey sent some reports back to England from the Alcantara on its troubled journey back. Did you watch the friendly fixtures between Exeter and Brazil in May 2004 and will you watch the one in July 2014? Would you like to send us some reports?

Whereas in the RAMM trails locations are tied to where objects in RAMM's collections were initially found, the locations forming part of the Exeter City Football Club Supporters Trust trails are tied to oral histories, only occasionally referring to artifacts by which to remember them. Each of the interpretation texts is meant to prompt an affordance facilitating users' in relating themselves to the physical sites and the stories narrated through them, and thus position themselves within the broader history of the Club and Trust in Exeter.

The second trail, written specifically for the children taking part in the Kick Start programme, utilizes only locations within St. James Park, and starts and ends at the Club's Chairman's Room. The trail comprises various stands in the grounds, the players' changing rooms, the media suites from which the press deliver their broadcasts, but also sites where specific fans stood, players displayed their skill, or memorable objects were on display, such as the trophy cabinet or the Brazilian flags. The class was divided in two groups of five to six children, and each group was given an iPad to interact with the Time Trails interface. We also, in case of poor connectivity on the day, prepared Quick Response codes (QR codes), and placed them strategically at the stadium. To be safe, we also brought paper versions of the texts. As the children passed each location, the Time Trails web app was activated, or the QR codes scanned, and information could be read. The task at this stage was for the children to absorb specific knowledge about the history of the Club and Trust, which they would write up on a note pad so that it could be used in the second part of the exercise. A member of the team operated as a guide, linking stories from our tour to an induction tour they had previously received by a member of the Kick Start programme, and ensuring they captured the relevant information for the second part of the exercise, while another member of the team documented the event for the Grecian Voices blog. The documentation had been a requirement to show the schools from which the children had 
come how they engaged with literacy and numeracy whilst using the Time Trails tool. At the end of the exercise, all children were asked to congregate in the Club's Chairman's Room, where they took on the role of Exeter City staff who had to persuade a foreign player, played by a member of the team, or, with the second group by a volunteer child, to join Exeter City Football Club by boasting about the successes in the history of the Club and Trust over the past hundred years. This allowed the team to test how much content had been absorbed and how the Time Trails tool could be used within an educational context.

Similarly to the longer trail, this one used the stories of wellknown players and specific moments in the history of the Club and Trust, but did not prompt the children to use social media to share their thoughts about it nor generally, did it shift from first to second and third person as that role was taken on by the guide:

29th August 1920 saw the turnstiles swing into action for the first time for a football league match. On this day, over 6,000 people made their way through the gates to watch Exeter beat Brentford 3-0, with William Wright scoring City's first ever league goal. Also on the pitch that day was local man and goalkeeper Dick Pym (b. 1893) who played for the club from 1911-1921. Pym initially followed the family profession as a fisherman, something he continued to do though his career and after. Known as 'fisherman', 'scissors' or 'pincher', Pym, who was one of the players who went to South America, though, curiously, he was apparently very sea sick during the journey, was later signed by Bolton Wanderer's for $£ 5,000$ - exactly the sum of money it cost the club to buy St. James Park outright on Friday 24 June 1921.

One of the most significant aspects of the history of the Club is the fact it is owned by the Trust, i.e. by its fans, and the trail attempted not only to identify the locations where this relationship was most visible, but also prompt the children to reflect about their own role as fans:

The turn of the Millennium saw troubled times at the park, with Exeter dropping out of the league on the verge of their 100 th anniversary. However things could have been much worse as City almost went out of existence entirely due to financial problems. Thankfully for the club, the Exeter City Supporters Trust stepped in and secured the future of the Grecians through business savvy, strong vision and, most importantly, coming together as a community. Exeter 
City FC became one of the first teams in the country to be recognized as a fan-owned club, always working hard in an effort to secure this dream and the future of the club. The emblem that stands right at the top of the stand represents the fans as the beating heart of Exeter City FC.

Initial findings about how users engaged with Time Trails revealed that they see the experience as an opportunity to generate new or lost knowledge about heritage, and that it is often the absence of an artifact, in the case of RAMM's trails, or an individual, in the case of the Exeter City Football Club Supporters Trust trails, from the site associated with it, that prompts users, especially in the case of the Exeter City Football Club trail, to relate their own story to the broader history of the Club and Trust. This absence causes a discrepancy between perceived, conceived and lived spaces, between physical and cultural spaces, between local and digital, archival spaces. In attempting to bridge these discrepancies, users plot their own stories within a broader history. This form of replay of archival materials, paired with the use of self-documentation of one's encounter with these materials, can be thus used as an aid to individuals to connect aspects of their own lives to specific environments and their histories.

We hope to have shown how Time Trails offers a novel way of encountering archival materials. To facilitate exploration, and in line with psychogeographical practices, we encouraged some level of meandering, both physical and mental, allowing to add to trails marking canonic trajectories information pertinent to how specific users participated in those trails. We often built in some level of performativity to prompt affordances and facilitate the adoption of different, more or less active roles that would encourage users to self-document via social media. This means that two distinctive processes of mapping and map-making occurred whilst using the Time Trails app and both played a fundamental role in terms of presencing. To explain this we need to dedicate some words to the subtle distinctions between the two.

Having been famously described as "[...] graphic representations that facilitate a spatial understanding of things, concepts, conditions, processes or events in the human world" (Harley; Woodward, 1987, p. xvi), maps are necessary orientation tools for mobile interpretation, i.e., the production of knowledge on the go. We know that maps 


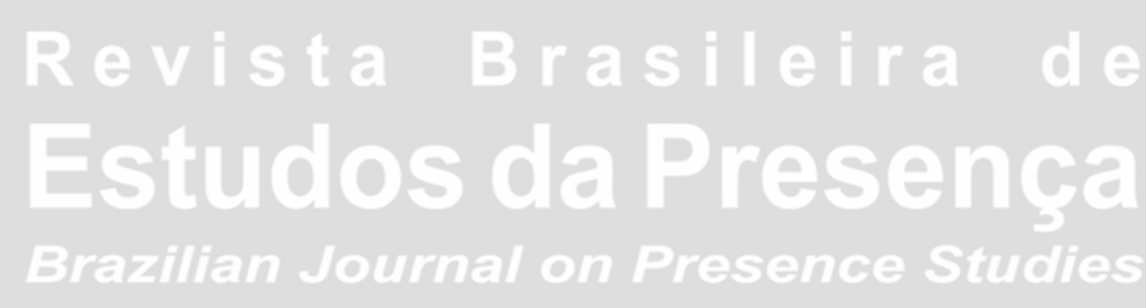

have often changed the way that people look at the world. We also know that historically map makers have wiped out entire areas simply to persuade people about where or how they should travel (such as the map Columbus used on his explorations which shows that there is hardly any distance between Europe and China by sea) or visualised the importance of certain socio-political groups by representing them at the centre (typically Google maps put us at the centre wherever we may be). Therefore maps are instruments of navigation, but also tools for the establishment of power, authority, presence and identity. Anthropologist Tim Ingold, for instance, notes that knowledge about the environment is in fact determined while we are on the move within it. In other words, the traveller maps, i.e. he "[...] knows as he goes" (2000, p. 231), and for him, mapping is writing $(2000$, p. 223). Thus a map is a navigational tool, but this tool is in fact generating and facilitating "[...] a social construction of reality", a "system[s] of signs" (Wood, 1993, p. 52). In Time Trails we map, i.e. we read the signs through which we choose to perceive our environment, and place ourselves within it, self-documenting the production of our knowledge onto an existing cartographic view, herewith map-making, i.e. documenting the processes through which we generate this knowledge onto a map so that others may use it. This documentation, which facilitates the generation of traces, is crucial in terms of reviewing one's presence.

Additionally to mapping, and map-making, Time Trails uses trails. A trail is a story about places and their subjective experience. Cartographically, trails have no value precisely because cartographies pretend universality and often attempt to hide a point of view, whereas trails are subjective. Maps in fact rarely show movement, rather they show places, temporary rests from the rhythms of life, which may be worth remembering. Conventionally places are configured on cartographic maps as enclosed dots, indicating that something is or has been present there. So, as we know, maps are about presence. This is why it is important that we map, that we establish our presence in space and time. Trails, on the other hand, join places and implicate more or less subjective movement. Trails are not roads, of course, though some trails may become roads. Rather, trails are subjective paths, points of observations, marking individual decisions and world-views. Trails too are about presence, but not so 
much of an object as of a subject, a person. In mixed reality, trails mark movement in space as well as trajectories through data. Here, trails mark the writing of one's story onto the broader map of the history of Exeter City Football Club and Trust.

To sum up, cartographic maps show a "bird-eye's view" (Gibson, 1979, p. 198-199) - they show what pretends to be an objective reality -; trails, on the other hand, show paths - they show subjective points of view. Maps are attempts towards more or less canonic and holistic world-views. Trails are individual stories, they mark the subjective experience of space. When Time Trails will be released to users, these will be able to use self-documentations to generate new trails, new stories, that use art, heritage, material and visual culture as a way of revisiting sites, histories and museum collections. Thus Time Trails would facilitate not only the act of map-making, stimulating our selfawareness of our relationship with these materials, but also generate a living performative archive that could be used by others, building a growing picture of how and possibly even why we interpret histories outside of the organizations that act as their custodians. We think that these individual journeys, increasingly, offer valuable knowledge to institutions, and it is the documentation and preservation of this knowledge that we need to focus on to make sure legacies of these processes will be there for future generations. This is because it is these individual encounters that extend the notion of what an artwork, a heritage site, a once loved object of visual and material culture is at a particular point in time and history, precisely because the artwork, an artifact or an item of visual and material culture is not just the object, but the network of the processes of presence that capture its reception by users over time. 


\section{Notes}

${ }^{1}$ Acknowledgements: we gracefully acknowledge Research and Enterprise in Arts and Creative Technology - Higher Education Innovation Funding (REACT-HEIF) for the funding of our research for Time Trails, the Arts \& Humanities Research Council (AHRC) for funding our research on presence and the Research Councils of the United Kingdom (RCUK) (EP/G065802/1) for funding our research on trajectories. We are grateful to the Kick Start programme for giving us the opportunity to test the trail and to all the children that took part in our first workshop on 4 October 2013 for their enthusiasm and feedback.

${ }^{2}$ Agradecimentos: somos gratos ao Research and Enterprise in Arts and Creative Technology - Higher Education Innovation Funding (REACT-HEIF) pelo financiamento de nossa pesquisa de Time Trails, ao Art and Humanities Research Council (AHRC) pelo financiamento de nossa pesquisa sobre presença e ao Research Councils of the United Kingdom (RCUK) (EP/G065802/1) pelo financiamento de nossa pesquisa sobre trajetórias. Agradecemos ao programa Kick Start por ternos dado a oportunidade de testar o circuito e a todas as crianças que participaram de nossa primeira oficina no dia 4 de outubro de 2013 por seu entusiasmo e resposta.

\section{References}

BENFORD, Steve; GIANNACHI, Gabriella. Performing Mixed Reality. Cambridge: The MIT Press, 2011.

CASTELLS, Manuel. The Rise of the Network Society. London: Blackwell, 1996.

GIANNACHI, Gabriella; KAYE, Nick. Performing Presence: between the live and the simulated. Manchester: Manchester University Press, 2011.

GIANNACHI, Gabriella. Environmental Presence. In: GIANNACHI, Gabriella; KAYE, Nick; SHANKS, Michael. Archaeologies of Presence: art, performance and the persistence of being. London and New York: Routledge, 2012. P. 50-63.

GRECIAN VOICES. Available at: <http://grecianvoices.wordpress.com/>. Accessed on: 26 sep. 2013.

GIBSON, James. The Ecological Approach to Visual Perception. Boston: Houghton Mifflin, 1979.

HARLEY, John Brian; WOODWARD, David (Org.). The History of Geography, vol. 1. Chicago: Chicago University Press, 1987.

HEIDEGGER, Martin. On the Way to Language. Translation: P. D. Hertz. New York: Harper and Row, 1971 [1959].

HEIDEGGER, Martin. An Introduction to Metaphysics. Translation: Ralph Manheim. New Haven and London: Yale University Press, 1979 [1959].

HUSSERL, Edmund. On the Phenomenology of the Consciousness of Internal Time. Translation: J. B. Brough. Dordrecht: Kluwer, 1990 [1928].

INGOLD, Tim. The Perception of the Environment. London and New York: Routledge, 2000 . 
LEFEBVRE, Henri. The Production of Space. Translation: D. Nicholson Smith. Oxford: Blackwell, 1992 [1974].

MILGRAM, Paul; KISHINO, Fumio. A Taxonomy of Mixed Reality Displays. IEICE Transactions on Information and Systems, [s.1.], v. E77-D, n. 12, p. 449-455, 1994.

WOOD, Denis. The fine line between mapping and mapmaking. Cartographica, Toronto, University of Toronto Press, v. 30, n. 4, p. 50-60, 1993.

Gabriella Giannachi is Professor in Performance and New Media at the University of Exeter, United Kingdom. She has published: Virtual Theatres (2004); The Politics of New Media Theatre (2007); Performing Presence: Between the Live and the Simulated, co-authored with Nick Kaye (2011); Performing Mixed Reality, co-authored with Steve Benford (2011); and Archaeologies of Presence, co-edited with Michael Shanks and Nick Kaye. She has written papers for a number of humanities and science journals, and has been an investigator in Performing Presence: from the Live to the Simulated (2004-2009) and Horizon Digital Economy Research (2009-2014). She is currently collaborating with Tate and Royal Albert Memorial Museum and Art Gallery to develop web apps that allow users to encounter and annotate museum collections outside the museum.

E-mail: g.giannachi@exeter.ac.uk

William Barrett is a Doctoral Candidate in the Centre for Intermedia at the University of Exeter and Royal Albert Memorial Museum and Art Gallery, working on the use of mobile apps to facilitate learning about digital heritage.

E-mail:wdpb201@exeter.ac.uk

Rick Lawrence completed a Bachelor of Arts with Honours in Ancient History and Archaeology from The University of Manchester in 1981. After working on Internet technologies and e-communications projects for the Department for Work and Pensions for over a decade, he decided on a career change and achieved a Postgraduate Certificate in Archaeology and Heritage Management from the University of Exeter in 2009. He is currently Digital Media Officer at the Royal Albert Memorial Museum and Art Gallery in Exeter. His current role involves managing the museum's online presence and digital strategy, fostering a digital culture among staff, ensuring digital targets are met, managing museum software interactives and leading on digital projects.

E-mail: ramm.digitalmedia@exeter.gov.uk

Thomas Cadbury, Dr, is Curator for Antiquities at Royal Albert Memorial Museum and Art Gallery. His collections responsibilities cover the archaeology, social history and numismatics of Exeter and Devon as well as the museum's collection of antiquities from the Mediterranean and Western Asia. Recent work has focused on the award- 
winning redevelopment of the museum and displays. The displays are object rich and the storylines collections led and although they draw on recent research they are inspired by the Victorian enthusiasm for investigating the world through collecting material culture.

E-mail: thomas.cadbury@exeter.gov.uk

Helen Burbage has a Bachelor of Arts with Honours in History from Durham University (2008) and a Master of Arts in Museum and Artefact Studies, also from Durham (2009). Following a collections management internship at the World Rugby Museum she moved to Exeter in 2010 to take up the role of Documentation Assistant at the Royal Albert Memorial Museum and Art Gallery. In 2012 she moved into the new role of Collections and Audiences Assistant. Her current role includes museum documentation, object photography, co-managing Royal Albert Memorial Museum and Art Gallery's social media presence and content generation for digital projects. E-mail: helen.burbage@exeter.gov.uk

Andy Chapman, 1010 Media, has developed online systems across a variety of sectors including Entertainment, Sports and TV Personalities, Commercial Business and Museum and Arts projects. He has over twelve years experience of commercial website development and delivery, including development in enterprise level government portals, international E-Commerce Platforms, National E-Mail marketing and advertising campaigns and many more lightweight high profile projects.

E-mail: a.chapman@1010media.co.uk

Paul Farley is a Trustee of Exeter City Football Club Supporters Trust and Chair of the Exeter City Football Club Community Working Group.

E-mail: paulfarley@supanet.com

This unpublished text, reviewed by Ananyr Porto Fajardo, is also published in Portuguese in this issue. 